\title{
Resveratrol intake during pregnancy and lactation re-programs adiposity and ameliorates leptin resistance in male progeny induced by maternal high-fat/high sucrose plus postnatal high-fat/high sucrose diets via fat metabolism regulation
}

Ta-Yu Liu ${ }^{1+}$, Hong-Ren Yu ${ }^{1+}$, Ching-Chou Tsai ${ }^{2}$, Li-Tung Huang ${ }^{1 * \dagger}$, Chih-Cheng Chen ${ }^{1}$, Jium-Ming Sheen ${ }^{1}$, Mao-Meng Tiao ${ }^{1}$, You-Lin Tain ${ }^{1}$, I-Chun Lin ${ }^{1}$, Yun-Ju Lai ${ }^{2}$, Yu-Ju Lin ${ }^{2}$ and Te-Yao Hsu ${ }^{2 *}$ (D)

\begin{abstract}
Background: Maternal obesity is an emerging problem in the modern world. Growing evidence suggests that intrauterine high-fat (HF) exposure may predispose progeny to subsequent metabolic challenges. Progeny born to mothers who ate an HF diet also tends to eat an HF diet when growing and aggravate metabolic issues. Thus, the generational transmission of obesity is cyclical. Developing a strategy to prevent the occurrence of metabolic syndrome related to prenatal and/or postnatal HF diet is important. In this study, the reprogramming effects of maternal resveratrol treatment for the progeny with maternal HF/postnatal HF diets were investigated.

Methods: Sprague-Dawley dams were fed either a control or a high-fat/high sucrose diet (HFHS) from mating to lactation. After weaning, the progeny was fed chow or an HF diet. Four experimental groups were yielded: CC (maternal/postnatal control diet), HC (maternal HF/postnatal control diet), CH (maternal control/postnatal HFHS diet), and HH (maternal/postnatal HFHS diet). A fifth group (HRH) received a maternal HFHS diet plus maternal resveratrol treatment and a postnatal chow diet to study the effects of maternal resveratrol therapy.

(Continued on next page)
\end{abstract}

\footnotetext{
* Correspondence: litung.huang@gmail.com; tyhsu@adm.cgmh.org.tw

${ }^{\dagger}$ Ta-Yu Liu and Hong-Ren Yu are co-first author.

${ }^{1}$ Department of Pediatrics, Kaohsiung Chang Gung Memorial Hospital,

Graduate Institute of Clinical Medical Science, Chang Gung University

College of Medicine, Kaohsiung, Taiwan

2Department of Obstetrics and Gynecology, Kaohsiung Chang Gung

Memorial Hospital, \#123, Ta-Pei Road, Niao-Sung District, Kaohsiung, Taiwan
}

C C The Author(s). 2020 Open Access This article is licensed under a Creative Commons Attribution 4.0 International License, which permits use, sharing, adaptation, distribution and reproduction in any medium or format, as long as you give appropriate credit to the original author(s) and the source, provide a link to the Creative Commons licence, and indicate if changes were made. The images or other third party material in this article are included in the article's Creative Commons licence, unless indicated otherwise in a credit line to the material. If material is not included in the article's Creative Commons licence and your intended use is not permitted by statutory regulation or exceeds the permitted use, you will need to obtain permission directly from the copyright holder. To view a copy of this licence, visit http://creativecommons.org/licenses/by/4.0/ The Creative Commons Public Domain Dedication waiver (http://creativecommons.org/publicdomain/zero/1.0/) applies to the data made available in this article, unless otherwise stated in a credit line to the data. 
(Continued from previous page)

Results: Maternal resveratrol treatment lessened the weight and adiposity of progeny that were programmed by combined prenatal and postnatal HFHS diets. Maternal resveratrol therapy ameliorated the decreased abundance of the sirtuin 1 (SIRT1) enzyme in retroperitoneal tissue and the altered leptin/soluble leptin receptor ratio of progeny. Maternal resveratrol therapy also decreased lipogenesis and increased lipolysis for progeny.

Conclusions: Maternal resveratrol intervention can prevent adiposity programmed by maternal and postnatal HFHS diets by inducing lipid metabolic modulation. This study offers a novel reprogramming role for the effect of maternal resveratrol supplements against obesity.

Keywords: Maternal resveratrol, Reprograms, Prenatal, Postnatal, High-fat diet, Adiposity, Leptin

\section{Background}

Obesity is one of the most important health challenges in the modern world. Many epidemiological studies have demonstrated a rapid increase in the prevalence of obesity [1]. Obesity is commonly associated with adverse consequences including chronic inflammation, type 2 diabetes, glucose intolerance, hypertension, cardiovascular problems, chronic kidney disease, and non-alcoholic fatty liver disease [2-8]. The equilibrium between energy intake (food consumption) and energy expenditure (basal metabolism, physical activity, and thermogenesis) is closely regulated in individuals. Obesity takes place when energy intake exceeds energy expenditure and is characterized by an excess of adipose tissue. Adipose tissue is now considered an active metabolic tissue that regulates metabolism and inflammation through adipokines, such as leptin, visfatin, apelin, resistin, and adiponectin [7, 9-12]. Leptin, the first adipocytokine recognized, acts on the brain and promotes satiety and energy consumption. Apart from the central nervous system, leptin receptors are expressed in many peripheral tissues and promote inflammation, glomerular endothelial cell proliferation, lipid metabolism, and insulin resistance $[11,13-15]$. Despite adequate leptin regulation, however, leptin resistance can occur in association with enhanced circulating leptin levels in obese humans resulting from relative insensitivity to leptin at its site of action [16].

The developmental origins of health and disease $(\mathrm{DOHaD})$ is a widely accepted concept today [17]. In determining the development of human diseases in adulthood, $\mathrm{DOHaD}$ emphasizes the role of prenatal and perinatal exposure to environmental factors [18-21]. Many pieces of evidence strengthening $\mathrm{DOHaD}$ science have been observed from animal models and human studies. Maternal obesity is an emerging problem globally, with over $30 \%$ of women of child-bearing age being classified as obese [22]. Growing evidence suggests that an intrauterine high-fat (HF) environment may predispose progeny to subsequent metabolic challenges, such as hypertension, diabetes, and metabolic syndrome [23-25]. Epigenetic modification (DNA methylation, histone modifications, microRNAs) is one the critical drivers for fetal over-nutrition and increased susceptibility to obesity development in adult life [25, 26]. Progeny born to mothers who ate an HF diet also tend to eat an HF diet when growing and have been found to develop metabolic problems [27, 28]. Thus, the generational transmission of obesity is cyclical [29].

Current treatment for metabolic syndrome relies on the long-term use of drugs in adults. However, these drugs are not always effective for all individuals and may cause certain side effects. It is important to develop a strategy to treat and prevent the occurrence of metabolic syndrome related to prenatal or postnatal HF diet in the modern world. Reprogramming refers to reversing the development of programming errors and resuming normal development through programming manipulation [30, 31]. Supplements present in the diet of pregnant women, such as vitamin D, glycine, folic acid, and fish oil, tend to attenuate the adverse consequences for progeny [32]. Resveratrol (3,4',5-trans-trihydroxystilbene), a natural polyphenolic compound produced in numerous plant species (grapes, peanuts, cocoa, certain berries) and red wine, is an activator of sirtuin 1 (SIRT1). It makes a substantial contribution for lipid and glucose regulation by deacetylating the crucial metabolic signals relevant to the AMP-activated protein kinase-SIRT1PPARG coactivator- $1 \alpha$ axis $[33,34]$. Resveratrol treatment has been shown to improve glucose homeostasis, lipid parameters, mitochondrial function, and body weight in rats consuming an HF diet [35]. Previous study also showed that resveratrol treatment for progeny improves some of the altered metabolic symptoms, peripheral leptin resistance, and related dysbiosis of the gut programmed by combined prenatal and postnatal HF diet exposure [36, 37]. Since maternal obesity can exert a negative effect on progeny beginning from embryo development, the potential implication of maternal resveratrol administration in reprogramming is worthy of investigating [38]. In this study, the preventive effects of maternal resveratrol supplements and its mechanisms in the male progeny of dams with high-fat/high-sucrose (HFHS) diets were investigated. 


\section{Materials and methods}

\section{Animals and experimental protocol}

This study was carried out according to the Guide for the Care and Use of Laboratory Animals by the National Institutes of Health and approved by the Institutional Animal Care and Use Committee of Kaohsiung Chang Gung Memorial Hospital (No. 2017032704) in compliance with the principles of the 3Rs (Replacement, Reduction and Refinement). Virgin Sprague-Dawley (SD) rats (BioLASCO Taiwan Co., Ltd., Taipei, Taiwan) were placed and maintained in a facility that approved by the Association for Assessment and Accreditation of Laboratory Animal Care International of Kaohsiung Chang Gung Memorial Hospital [39]. Female rats received either a regular rat diet (Fwusow Taiwan Co., Ltd., Taichung, Taiwan; 52 g\% carbohydrates, $23.5 \mathrm{~g} \%$ protein, $4.5 \mathrm{~g} \%$ fat, $10 \mathrm{~g} \%$ ash, and $8 \mathrm{~g} \%$ fiber) or an HFHS diet (D12331, Research Diets, Inc., New Brunswick, NJ, USA; $35.8 \mathrm{~g} \%$ fat plus high sucrose [35.5 g\% carbohydrate], and protein $23.0 \mathrm{~g} \%$ ) ad libitum for 8 weeks before mating and during gestation and lactation. Male SD rats were kept with female rats until mating was confirmed [36, 40]. The size of the litter was normalized after delivery immediately to conform the amount of milk and maternal care equalized. A maximum of three male progenies was taken from each dam to avoid litter effects. Male progeny were supplemented with either regular food or an HFHS diet since weaning to four-month-old and were placed in four experimental groups based on the diet regimen: CC (maternal chow diet/postnatal chow diet), $\mathrm{CH}$ (maternal chow diet/postnatal HFHS diet), HC (maternal HFHS diet/postnatal chow diet), and $\mathrm{HH}$ (maternal HFHS diet/postnatal HFHS diet) ( $n=10-12$ for each group). Additionally, a maternal intervention group (HRH) with $50 \mathrm{mg} / \mathrm{L}$ resveratrol (Sigma-Aldrich, St. Louis, MO, USA) in drinking water for dams on the maternal HFHS diet/postnatal HFHS diet during pregnancy and lactation was created for comparison. The protocol for resveratrol preparation was as follows: $50 \mathrm{mg}$ of resveratrol was dissolved in $30 \mathrm{ml} 20 \% 2$-Hydroxypropyl- $\beta$ cyclodextrin solution (Sigma-Aldrich, St. Louis, MO, USA), then dispensed into $1 \mathrm{~L}$ by distilled water.

\section{Experimental processes for sample collections}

Progeny body weight (BW) was determined every month since birth to four-month-old. At four-month-old, the rat progeny was sacrificed under anesthesia of Zoletil (Zoletil $^{\circ}$ 50; Virbac corporation, Carros, France) and xylazine (Rompun ${ }^{\oplus}$, Bayer, Leverkusen, Germany), and blood samples were obtained by cardiac puncture as previously reported [39-41]. Retroperitoneal, mesenteric, epididymal, and subcutaneous fats were collected to measure adipose tissue weight [41]. Retroperitoneal fat was selected for further biomolecular studies for its more correlation to metabolic profiles than other fat tissues $[41,42]$.

\section{Determination of plasma parameters and histological examinations}

Plasma liver enzymes and cholesterol were measured by using chemistry analyzer (FUJI DRI-CHEM NX500, Tokyo, Japan). Plasma leptin and soluble leptin receptor (sOB-R) levels were determined by ELISA (Biovendor, Brno, Czech Republic, and BlueGene, Shanghai, China). The fat tissues were fixed in $10 \%$ formalin (Wako Junyaku, Osaka, Japan), and four micrometer-thick sections were stained with hematoxylin and eosin for morphometric evaluation. Images were taken by a mounted digital camera under a Nikon Eclipse E600 microscope on 10 low-power (magnification, $\times 40$ ) fields (Nikon, Melville, NY, USA).

\section{Quantitative reverse transcription-polymerase chain reaction (RT-qPCR)}

Total RNA extracted from adipose tissue was used to generate cDNA with Moloney-murine leukemia virus reverse transcriptase as previous reported [39]. RT-qPCR was carried out for FAS (fatty acid synthase), LPL (lipoprotein lipase), leptin, and leptin receptor. GAPDH (glyceraldehyde 3-phosphate dehydrogenase) gene expressions were utilized to normalized the genes. qPCR was carried out with SYBR Green PCR Master Mix (Thermo Fisher Scientific, San Jose, CA) containing 10 $\mathrm{mM}$ forward and reverse primers. The cycling protocol was conducted as previously reported [36, 41]. The threshold cycles $(\mathrm{Ct})$ were determined with Light Cycler software (ver. 1.5.0) and the relative quantification of mRNA expression was evaluated by compared Ct [3941]. The primer sequences used were provided in Supplementary Table 1.

\section{Western blotting}

Adipose tissue $(50 \mathrm{mg}$ ) was homogenized and extracted with a protein extraction solution (iNtRON Biotechnology Inc., Seongnam, South Korea). After the concentration was evaluated by using protein assay kit (Bio-Rad, Hercules, CA, USA), samples were mixed with a sample buffer, boiled, and indicated to electrophoresis using sodium dodecyl sulfate-polyacrylamide gels [36]. After transfer to a polyvinylidene fluoride membrane (Millipore, Bedford, MA, USA) and blocking with phosphatebuffered saline-Tween ( $5 \%$ skim milk), the membranes were immersed with the following first antibodies: SIRT1, (\#ab110304, Abcam, Cambridge, MA, USA), FAS (Abcam, Cambridge, MA, USA), and LPL (Abcam, Cambridge, MA, USA) for $2 \mathrm{~h}$. The membranes were then immersed for $1 \mathrm{~h}$ with peroxidase-labeled secondary antibody diluted in TBS-Tween after washing with 
$0.1 \%$ T-TBS. After soaking with TBS-Tween, the membranes were developed using the ChemiDoc XRS (BioRad Laboratories, Hercules CA) to image the blots and Image Lab v5.0 (Bio-Rad, Hercules, CA, USA) to determine the density for each band as the integrated optical density after subtraction of background. The integrated optical density was factored for Ponceau red staining to correct protein loading. The relative abundances of proteins were determined with western blotting, as previously reported [41].

\section{Statistical analysis}

Two-way analysis of variance (ANOVA) was utilized to estimate the consequence of maternal HFHS diet and postnatal HFHS diet as dependent variables. Bonferroni correction was used to determine the subsequent simple-effects. The differences between the $\mathrm{HH}$ and HRH groups was used by Mann-Whitney $U$ test. Data were demonstrated as mean \pm standard error (SEM). For all tests, two-sided $P$-values less than 0.05 were tested as arrive statistical significance by using SPSS 22.0 for Windows XP (SPSS, Inc., Chicago, IL, USA).

\section{Results}

Maternal resveratrol therapy lessens weight and adiposity of progeny caused by prenatal and postnatal HF diet exposure

Supplementary Table 2 showed the body weight (BW) changes of dams in different groups. A HFHS diet led to heavier BW than control diet for dams. The birth BW and growth BW of progeny in different groups were shown in Supplementary Table 3 and Supplementary Table 4, respectively. There was a significant positive interaction between maternal HFHS (equivalent to Hit 1) and postnatal HFHS diets (Hit 2) on progeny BW and adipose tissue (Fig. 1a and b). Combined maternal HFHS and postnatal HFHS diets showed a synergetic effect leading to a higher BW and total adipose tissue weight

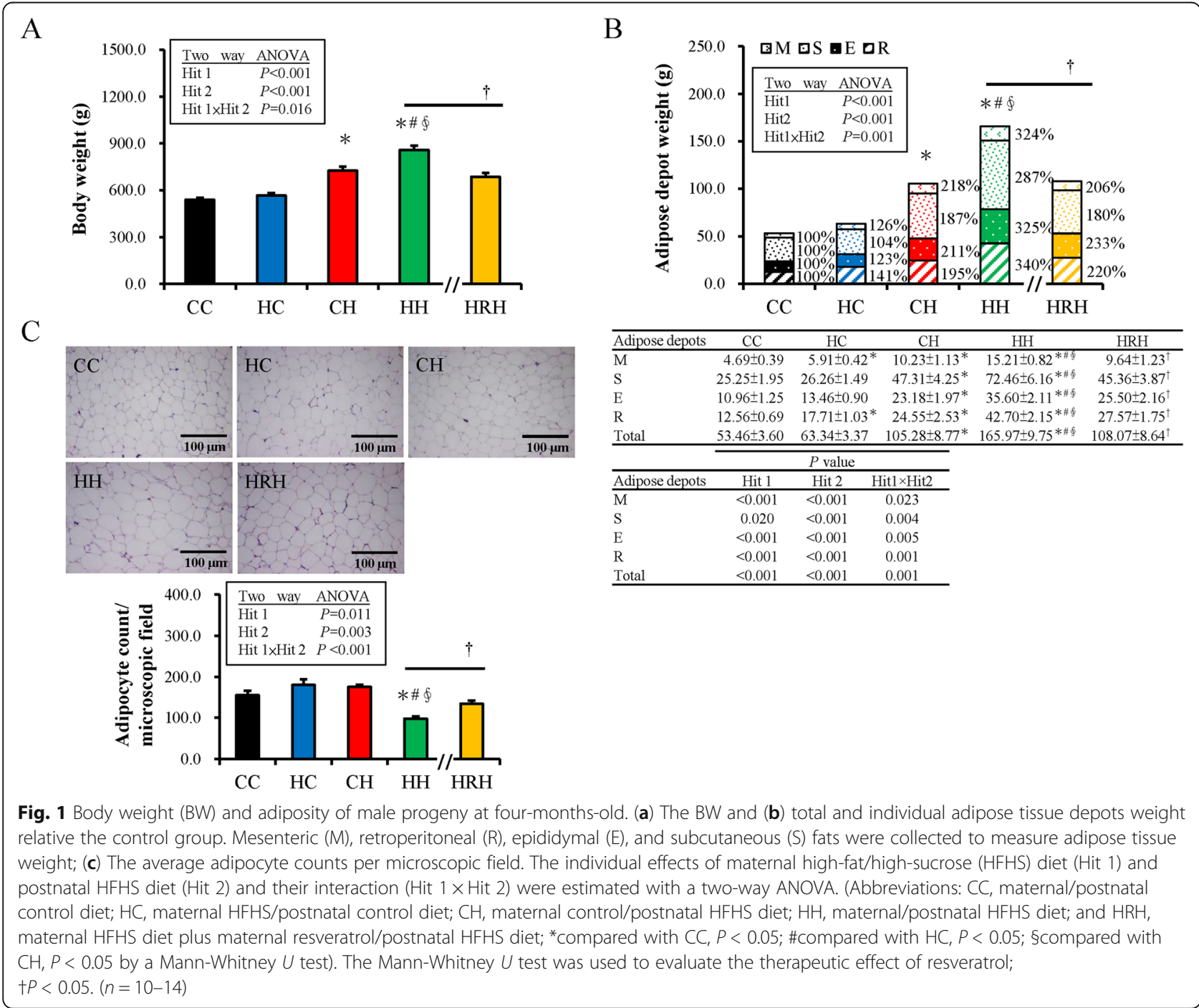


observed in the $\mathrm{HH}$ group at four-months-old. The effects of the prenatal HFHS diet [BW, F $(1,53)=13.92$, $P<0.001$; total adipose tissue weight, $\mathrm{F}(1,53)=23.43$, $P<0.001]$, and postnatal HFHS diet [BW, $F(1,53)=$ 124.61, $P<0.001$; total adipose tissue weight, $\mathrm{F}(1,53)=$ 112.22, $P<0.001]$ were shown respectively. Maternal and postnatal HFHS diet revealed a positive interactive effect on BW $[\mathrm{F}(1,53)=6.14, P=0.016])$. Furthermore, maternal and postnatal HFHS diets also resulted in the heaviest BW and total adipose tissue weight for the $\mathrm{HH}$ group. Maternal resveratrol treatment (HRH group) significantly decreased the BW $(685.86 \pm 23.95$ vs. $858.79 \pm$ $27.56 \mathrm{~g}, P<0.001)$ and total adipose tissue weight gains $(108.07 \pm 8.64$ vs. $165.97 \pm 9.75 \mathrm{~g}, P<0.001)$ observed in the $\mathrm{HH}$ group (Fig. 1a and b). For different fat depots, a two-way ANOVA analysis showed that both maternal HFHS and postnatal HFHS diets had a powerful impact on weight increase in four fat depots with Hit 1 /Hit 2 interactions (Fig. 1b). In addition, a maternal HFHS diet had more effects on weight gain in visceral fat depots (retroperitoneal and mesenteric) compared to subcutaneous fat. Maternal resveratrol intervention rescued the adiposity of all four fat depots introduced by prenatal and postnatal HFHS diets. Hematoxylin and eosin staining for progeny retroperitoneal fat tissue (Fig. 1c) revealed the $\mathrm{HH}$ group had the least adipocyte counts (largest adipocyte size) in a fixed microscopic field than the other groups. Maternal resveratrol therapy also decreased the adipocyte size of retroperitoneal tissue caused by prenatal and postnatal HFHS diets. These results suggest a synergic effect of maternal and postnatal HFHS diets on BW and total adipose tissue weight of progeny. This effect was suppressed and reprogrammed by maternal resveratrol therapy.

For liver function markers, glutamic oxaloacetic transaminase and glutamic pyruvic transaminase of the different groups showed that both maternal HFHS and postnatal HFHS diets significantly affected liver function (Fig. 2a and b). Resveratrol treatment (HRH) significantly improved the liver function observed in the $\mathrm{HH}$ group. Further, the total cholesterol level increased with both maternal and postnatal HFHS diets (Fig. 2c).

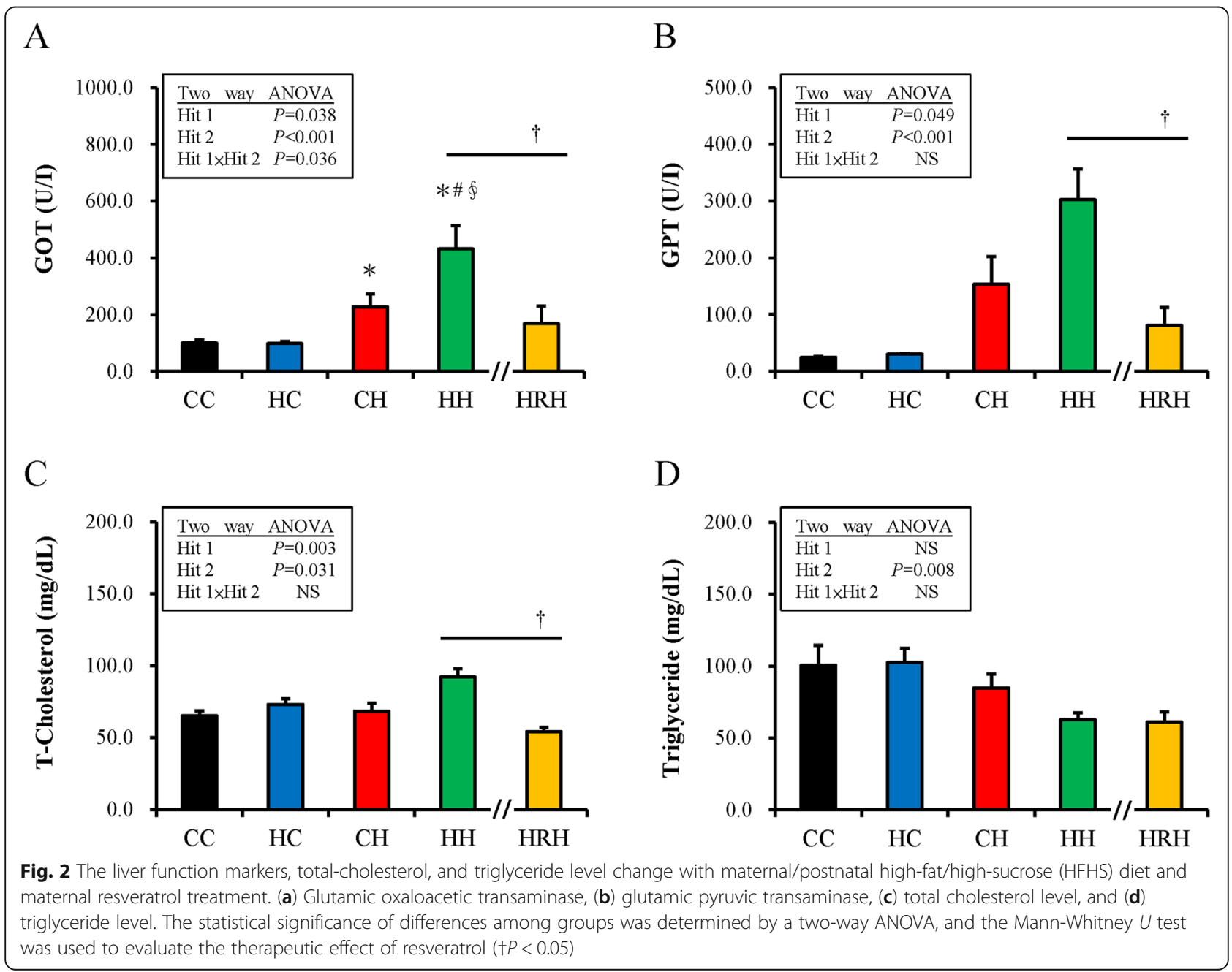


Resveratrol treatment (HRH) ameliorates the increased total cholesterol level in the $\mathrm{HH}$ group. However, no significant difference was shown in the triglyceride level between the $\mathrm{HH}$ and $\mathrm{HRH}$ groups (Fig. 2d).

\section{Maternal resveratrol treatment rescued the obesity programmed by prenatal and postnatal HFHS diets by total food intake reduction and metabolic modulation} The monthly sum of total calorie intake is shown in Fig. 3a. For the total calorie intake over 4 months, a two-way ANOVA analysis showed that both maternal HFHS [Hit1 $F(1,53)=0.11, P=0.001$ ] and postnatal HFHS diets $[F(1,53)=19.62, P<0.001]$ have significant impacts on total calorie intake without interaction [F (1, 53) $=0.13, P=0.076]$ (Fig. 3b).

For the total calorie intake over 4 months, the $\mathrm{HRH}$ group revealed less calorie intake than the $\mathrm{HH}$ group $(10,526.41 \pm 237.12$ vs. $11,519.01 \pm 333.50 \mathrm{Kcal}$, $P=0.01)$. On the other hand, as the calorie taking for each unit of BW was considered, progeny showed the most calorie intake per unit BW at two-months-old compared to other stages on average (Fig. 3c). For the calorie intake of per unit BW, a two-way ANOVA between groups analysis showed a significant main influence for postnatal HFHS from two- to four-montholds without a maternal HFHS /postnatal HFHS diet interaction (Fig. 3d). It is interesting to note that the $\mathrm{HRH}$ group had more calorie ingestion per unit BW than the $\mathrm{HH}$ group for the total four-month period $(24.41 \pm 0.17$ vs. $23.57 \pm 0.09 \mathrm{Kcal} / g, P<0.001)$, although the total calorie intake was less than the $\mathrm{HH}$ group during the four-month period ( $\mathrm{HRH}$ vs. $\mathrm{HH}$ : $24.41 \pm 0.17$ vs. $23.57 \pm 0.09 \mathrm{Kcal} / g, P<0.001$ ) (Fig. $3 \mathrm{~d})$. The impact of intrauterine resveratrol administration on energy expenditure seems attenuated when littermates are high-fat fed. Thus, the re-programming consequence of prenatal resveratrol on BW and adiposity of progeny occurred through both appetite reduction and metabolic modulation.

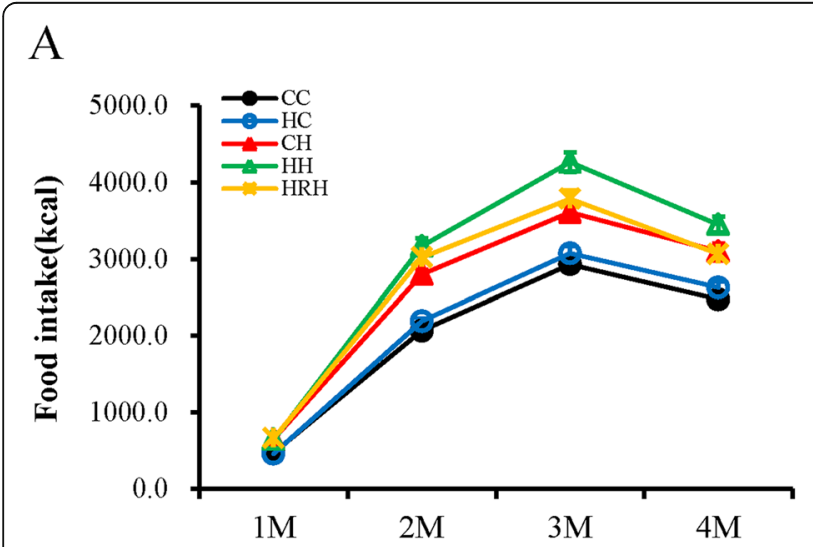

B

$\mathrm{C}$

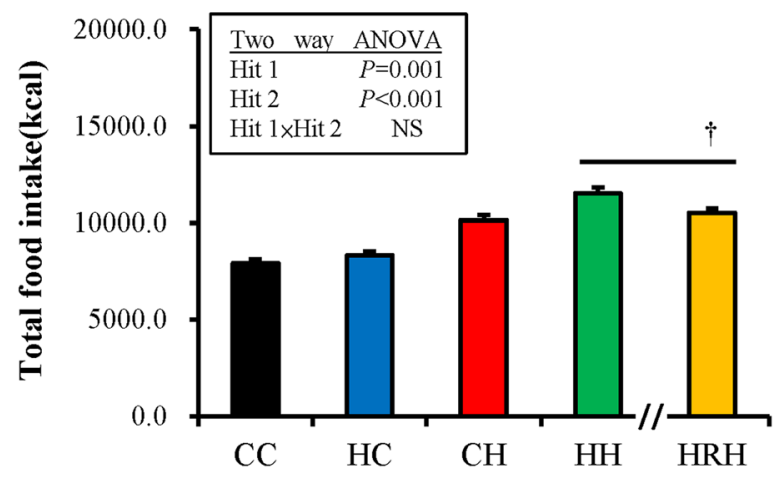

$\mathrm{D}$
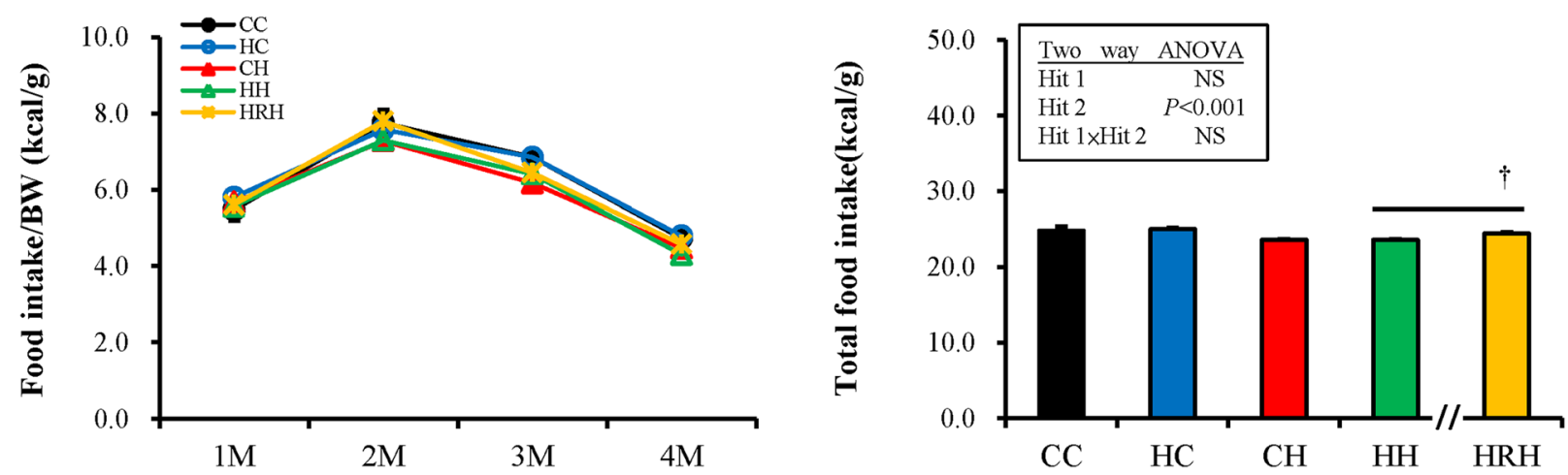

Fig. 3 Total calorie taking and calorie taking for each unit of body weight among different groups. (a) Monthly calorie taking from birth to fourmonths-old; (b) Total calorie intake for the four-months period; (c) Monthly calorie intake per unit body weight from birth to four-months-old; (d) Total calorie intake per unit of body weight for the four-months period. Abbreviations: CC, maternal/postnatal control diet; HC, prenatal high-fat/ high-sucrose (HFHS) /postnatal control diet; CH, prenatal control/postnatal HFHS diet; HH, maternal/postnatal HFHS diet; and HRH, maternal HFHS diet plus prenatal resveratrol/postnatal HFHS diet). The effects of maternal HFHS, postnatal HFHS diet, and their interaction were determined using two-way ANOVA. The Mann-Whitney $U$ test was used to evaluate the therapeutic effect of resveratrol $(+P<0.05)$ 
Maternal resveratrol treatment improves the decreased SIRT1 abundance of retroperitoneal tissue mediated by the united influence of prenatal and postnatal HFHS diets SIRT1 makes a substantial contribution in lipid and glucose regulation by deacetylating the master metabolic and inflammatory signals. Resveratrol is known as a SIRT1 activator. Further study was conducted to investigate the manifestation of SIRT1 by an HF diet and maternal resveratrol intervention. As showed in Fig. 4a, postnatal HFHS rather than maternal HFHS exposure significantly decreased the expression of SIRT1 mRNA [Hit 1: F $(1,44)=1.37, P=0.248$; Hit 2: F $(1,44)=109.78$, $P<0.001 ; \mathrm{H} 1$ and $\mathrm{H} 2$ interaction: $\mathrm{F}(1,44)=2.573, P=$ 0.116 . Maternal resveratrol treatment (HRH group) significantly ameliorated the decrease of SIRT1 mRNA caused by maternal HFHS diet plus postnatal HFHS diet (HH group) $(P=0.015)$. Further, the abundance of SIRT1 in adipose tissue was determined by western blotting (Fig. 4b). SIRT1 abundance was also significantly attenuated in the $\mathrm{HH}$ group. A maternal HF diet could aggravate the decrease of SIRT1 abundance induced by a postnatal HFHS diet [Hit 1: $F(1,28)=0.92, P=0.346$; Hit 2: $\mathrm{F}(1,28)=11.41, P=0.002 ; \mathrm{H} 1$ and $\mathrm{H} 2$ interaction: $\mathrm{F}$ $(1,28)=6.27, P=0.018]$. It was found that maternal resveratrol treatment also improves the reduced SIRT1 protein amount in retroperitoneal adipose depot mediated by prenatal HFHS and postnatal HFHS diets $(P=0.005)$.

\section{Maternal resveratrol treatment attenuates leptin resistance programmed by maternal and postnatal HFHS diets}

In further analysis, the plasma leptin and sOB-R levels were determined. Both maternal HFHS and postnatal HFHS diet exposure significantly increased plasma leptin levels [Hit 1: $\mathrm{F}(1,44)=25.93, P<0.001$; Hit2: $\mathrm{F}(1,44)=$ 66.69, $P<0.001]$. An interactive result of Hit 1 and Hit 2 for plasma leptin was identified $[F(1,44)=9.20, P=$ 0.004]. A maternal HFHS diet acting in synergy with a postnatal HFHS diet raised plasma leptin concentration, as observed in the $\mathrm{HH}$ group, that could be relieved by maternal resveratrol treatment $(\mathrm{HH}$ vs. $\mathrm{HRH}: 39.16 \pm$ 3.81 vs. HRH: $18.12 \pm 2.26 \mathrm{ng} / \mathrm{ml}, P<0.001$ ) (Fig. 5a).

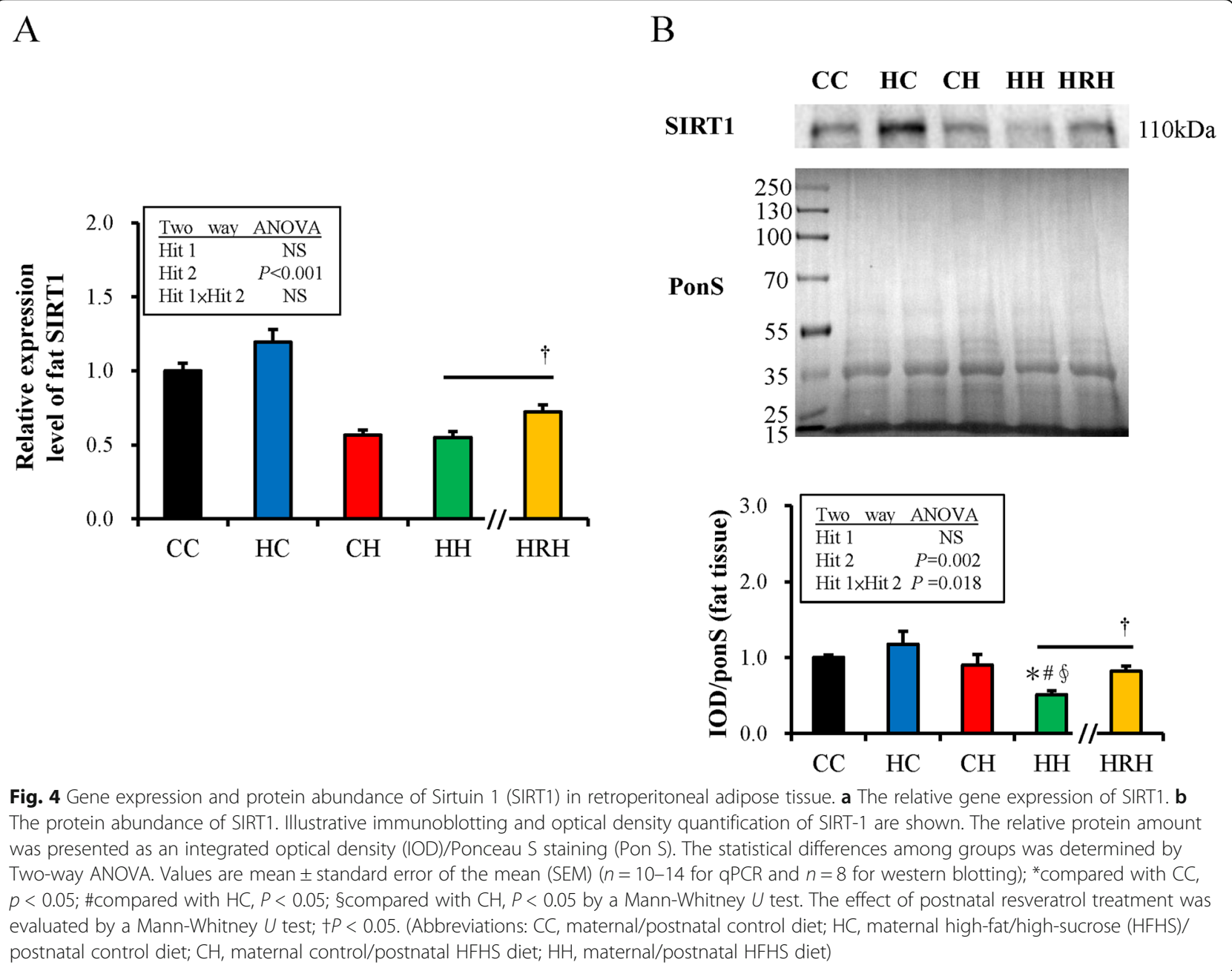




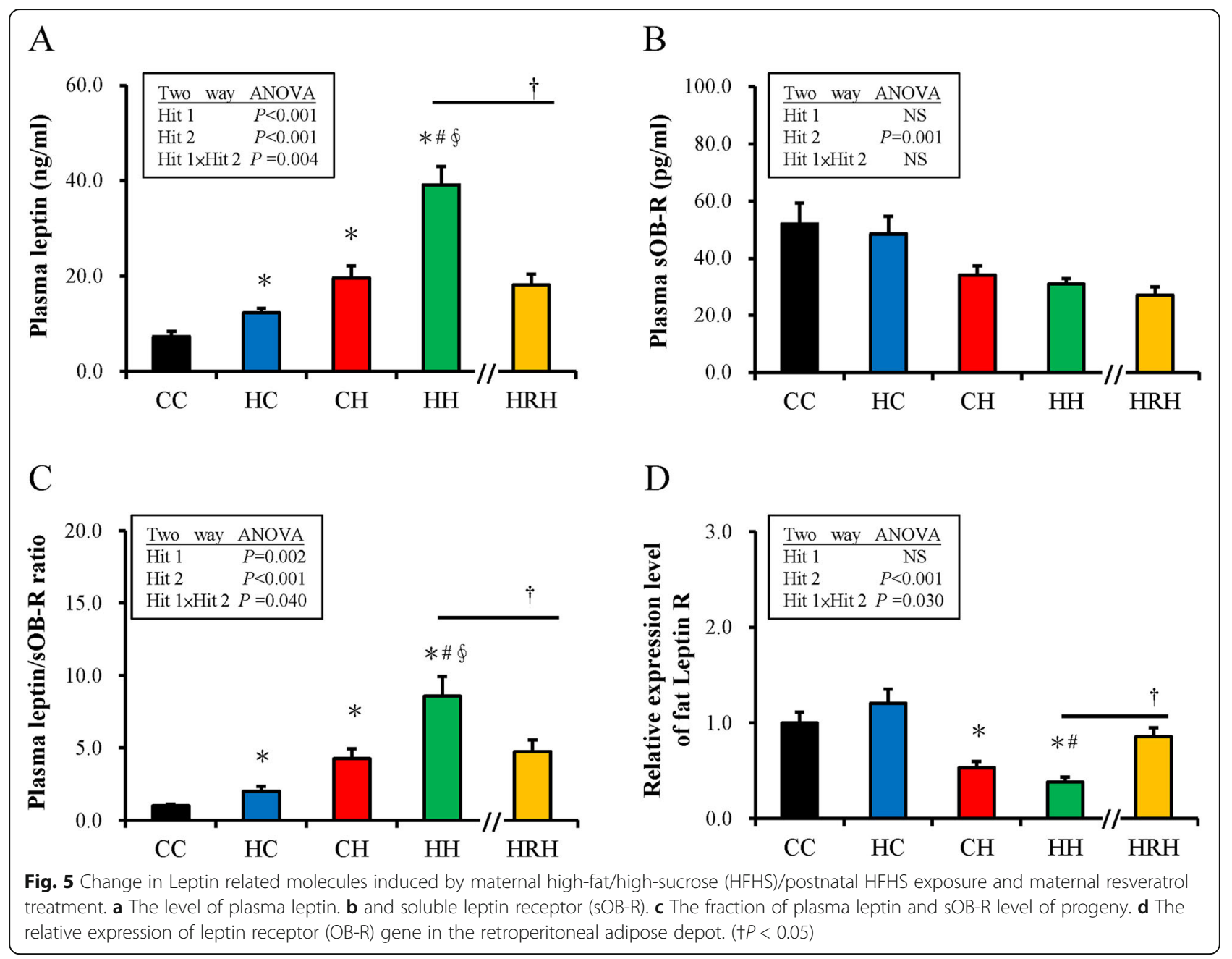

Figure $5 \mathrm{~b}$ showed that plasma sOB- $\mathrm{R}$ significantly decreased with a postnatal HFHS diet $[\mathrm{F}(1,44)=11.71, P=$ $0.001]$ but not prenatal HF diet exposure $[\mathrm{F}(1,44)=0.41$, $P=0.528]$ without Hit $1 /$ Hit 2 interaction. Maternal resveratrol treatment could not restore the decrease of plasma sOB-R in the HH group $(P=0.356)$. The Ratio of total leptin to sOB-R level is a biological marker for leptin resistance [43-45]. Thus, the ratio of leptin to SOB-R was examined and both prenatal HFHS and postnatal HFHS diets increased the leptin/sOB-R ratio in progeny [Hit 1: F $(1,44)=0.38, P=0.002$; Hit 2: F $(1,44)=59.54$, $P<0.001 ; \mathrm{H} 1$ and $\mathrm{H} 2$ interaction: $\mathrm{F}(1,44)=5.02, P=$ 0.040]. Progeny that received prenatal HFHS and postnatal HFHS diets had the highest leptin/sOB-R ratio. Maternal resveratrol treatment ameliorated the high leptin/sOB-R ratio induced by maternal HFHS and postnatal HFHS diet exposure (HH vs. HRH: $8.57 \pm 1.35$ vs. $4.73 \pm 0.82, P=0.049$ ) (Fig. $5 \mathrm{c}$ ). Thereafter, the gene expressions of the leptin receptor (OB-R) in retroperitoneal adipose tissue were evaluated using qPCR. Similar to sOB-R level, a postnatal HFHS diet, but not prenatal
HFHS diet, attenuate the expression of OB-R mRNA in the retroperitoneal adipose depot of progeny (Fig. 5d). Prescription of maternal resveratrol partially rescued the decreased gene expression of OB-R induced by prenatal and postnatal HFHS diet exposure $(P=0.001)$.

\section{Maternal resveratrol therapy alleviates lipogenesis and increases lipolysis to achieve an anti-obesity effect} Maternal resveratrol supplementation seems to result in an anti-obesity effect on progeny partially through metabolic modulation. Thus, the change in the manifestation of FAS and LPL genes in the retroperitoneal adipose depot was investigated to determine the lipid modulatory effects of resveratrol. Figures $6 \mathrm{a}$ and $\mathrm{b}$ showed that postnatal HFHS diet exposure significantly amplified the expression of the FAS gene [F $(1,36)=40.63, P<0.001]$ in retroperitoneal fat tissue, while both maternal HFHS [F $(1,44)=4.67, P=0.036]$ and postnatal HFHS diets [F $(1,44)=20.22, P<0.001]$ attenuated the expression of the $L P L$ gene in adipose tissue without a Hit $1 /$ Hit 2 interaction. The relative protein abundances of FAS and LPL 


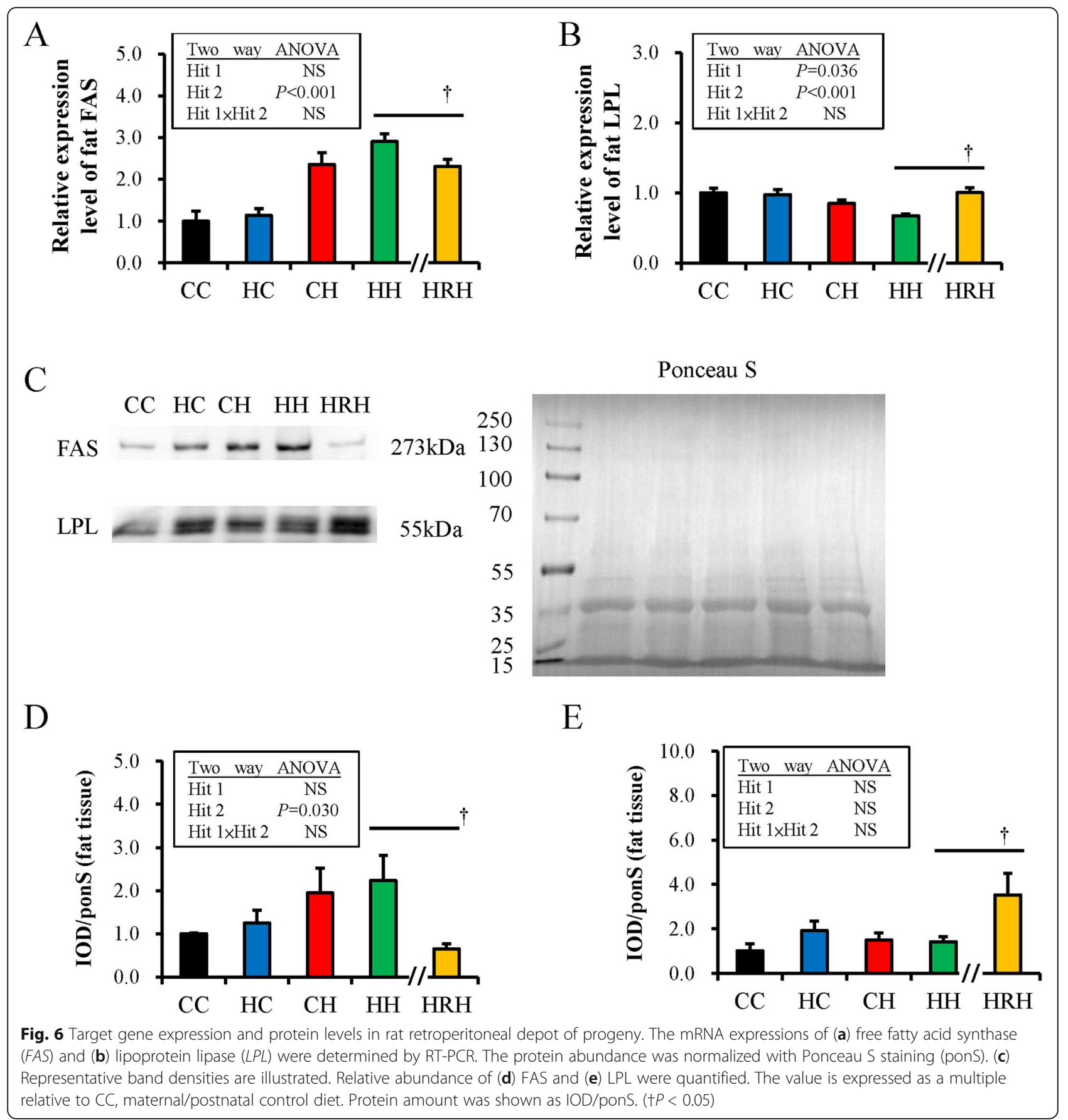

in retroperitoneal adipose tissue were also evaluated by western blotting. Figure $6 \mathrm{c}$ showed that the abundance of FAS increased with postnatal HFHS diet exposure [F $(1,31)=5.14, P=0.030]$ without Hit $1 /$ Hit 2 interaction. The abundance of LPL was not influenced by maternal or postnatal HFHS diet (Fig. 6d). Resveratrol treatment $(\mathrm{HRH})$ significantly decreased the gene expression and protein abundance of FAS of the retroperitoneal adipose depot as compared with the HH group (Fig. 6a and c). Resveratrol treatment ( $\mathrm{HRH})$ also increased the gene expression and protein abundance of LPL observed in the HH group (Fig. $6 \mathrm{~b}$ and d). Therefore, resveratrol decreases lipogenesis and increases lipolysis, resulting in an anti-obesity effect.

\section{Discussion}

This study showed that maternal resveratrol treatment lessens the weight and adiposity of progeny that were programmed by combined prenatal and postnatal HF diets. Maternal resveratrol supplementation achieved a 
therapeutic effect for progeny through food intake reduction and metabolic modulation. Maternal resveratrol therapy also ameliorated the decreased SIRT1 protein abundance of retroperitoneal tissue mediated by the synergetic influence of maternal and postnatal HFHS diet exposure. Moreover, maternal resveratrol treatment could alleviate the altered leptin/sOB-R ratio of progeny that had been programmed by prenatal and postnatal HFHS diets. Maternal resveratrol therapy decreased lipogenesis and increased lipolysis for progeny, resulting in an anti-obesity effect. Thus, prenatal resveratrol has the potential to serve as a preventative strategy for HFHS diet-induced obesity.

A previous study showed that resveratrol treatment for progeny after weaning could lessen the adiposity programmed by combined maternal plus postnatal HFHS diets through lessening intake or inducing metabolic changes [36]. Here, resveratrol was administrated for dams rather than progeny to determine the preventative effect of maternal resveratrol treatment for prenatal and postnatal HFHS diet exposure. The study showed that maternal resveratrol supplementation also has an antiobesity/anti-adiposity effect for progeny that were exposed to maternal and postnatal HFHS diets through lessening intake or inducing metabolic changes. Similar to postnatal resveratrol treatment [36], maternal resveratrol therapy could also activate the decreased SIRT1 amount in progeny retroperitoneal fat depot programmed by prenatal and postnatal HFHS diets. Both prenatal and postnatal resveratrol supplementation could decrease the altered plasma leptin levels in progeny induced by maternal and postnatal HFHS diet exposure. Thus, maternal resveratrol treatment has reprogramming effects on the adverse impacts of prenatal and postnatal HFHS diet environments. However, although both maternal resveratrol and postnatal resveratrol treatments demonstrated anti-obesity and metabolic modulatory effects for prenatal and postnatal HFHS diets, they utilized several different therapeutic mechanisms. First, in this study, when the calorie intake per unit BW was considered, the $\mathrm{HRH}$ group had more calorie ingestion per unit BW than the $\mathrm{HH}$ group, although the total calorie intake was less than the $\mathrm{HH}$ group during the four-month period. Thus, the reprogramming effects of maternal resveratrol treatment on the adiposity of progeny mainly occur through metabolic modulation. Second, postnatal resveratrol treatment exceedingly increased the gene expression of leptin receptors in retroperitoneal adipose tissue of progeny (almost 40 times compared to the control group). In contrast, that maternal resveratrol treatment (HRH group) could only partially ameliorate the decreased expression of the leptin receptor mRNA observed in the $\mathrm{HH}$ group and does not lead to as much improvement as postnatal resveratrol therapy. Thus, the DNA methylation of leptin receptors was not analyzed in this study. Third, maternal resveratrol treatment significantly ameliorated the decrease in expression of the $L P L$ gene in the $\mathrm{HH}$ group, while postnatal resveratrol treatment does not influence the expression of the $L P L$ gene.

A study from $\mathrm{Hsu}$, et al. had shown that maternal HFHS diet reduce adiponectin, SIRT1, p-AKT, and brain-derived neurotrophic factor (BDNF) of fetal brain and adult progeny hippocampus [46]. Maternal resveratrol treatment could renovate hippocampal p-AKT and BDNF of adult progeny with prenatal HFHS plus postnatal HFHS diet [46]. Maternal resveratrol supplementation seems reach both the central and peripheral tissues of the progeny. Maternal HF diet was proven to increase the proliferation of hypothalamic peptide-producing neurons of progeny and was claimed related to longterm preference for HF diet and obesity [47]. Whether prenatal resveratrol can modulate the altered neurotransmitters induced by maternal HF exposure is an interesting issue and need further studies. Maternal resveratrol therapy was also reported to reverse the insulin resistance induced by combined maternal HF plus postnatal HF diet exposure [46, 48]. The beneficial effects of resveratrol in HF exposed dams may have been indirect, as possibly related to glucose-lowering and insulin-sensitizing activities.

Resveratrol has many biological effects, such as anticancer, antioxidant, and anti-inflammatory characteristics [49]. Resveratrol can also be used to prevent heart disease and other diseases associated with aging. Other studies have revealed that resveratrol can prevent hepatic lipid accumulation induced by an HFHS diet [49-51]. The influence of maternal resveratrol supplementation on progeny has also been discovered recently. It has been shown that maternal resveratrol therapy can prevent cognitive decline in senescent mice progeny [52]. Tanaka et al. recently reported that prenatal resveratrol administration during lactation could decrease liver fatty acid synthesis of adult male rat progeny [53]. Maternal resveratrol administration can induce the activation of AMP-activated protein kinase through SIRT1 upregulation in the livers of adult male rat progeny. Therefore, the proteolytic processing of sterol regulatory element-binding protein-1c suppresses the gene expression of downstream lipogenesis-related enzymes, such as FAS and acetyl-CoA carboxylase in the livers of adult male progeny [53]. It has also previously been shown that maternal resveratrol intake protects against dysfunction of the islet and gestational diabetes-induced glucose intolerance in rat progeny [54]. Resveratrol supplementation for HFHS diet-fed pregnant mice also could promote brown and beige adipocyte development, thereby increasing energy expenditure and protecting progeny 
from HFHS diet-induced obesity and insulin resistance in adulthood. Thus, maternal resveratrol administration seems to protect progeny against postnatal HF dietinduced obesity $[55,56]$. Here, further evidence is provided that showing the anti-obesity/anti-adiposity effect of maternal resveratrol treatment on prenatal and postnatal HF diet exposure.

The multi-faceted actions of resveratrol are mediated by its regulatory functions on key transcription factors and kinases, such as NF-kB, cytochrome P450, p53, mTOR, cyclins, AKT, AMPK, SIRT1, PGC- $1 \alpha$ that modulate metabolism $[35,57]$. Whether maternal resveratrol still exerts such versatile functions for progeny is not clear now. Previous study had shown that resveratrol therapy can improve the plasma propionate level, dysregulated metabolic parameters, and dysbiosis related to maternal HFHS plus postnatal HFHS diet exposure [37]. More studies are needed to clarify the effect of maternal gut microbiota changes on the metabolism of progeny.

Caloric restriction has been shown to elongate lifespan in mammals through the activation of SIRT1 that regulate cellular energy metabolism and redox state [58]. Resveratrol seems like caloric restriction by enhancing SIRT1/PGC-1 $\alpha$ signaling pathway and mitochondrial biogenesis that linked to the regulation of the vitagene system and metabolism homeostasis [58-61]. Given the relationship between redox status and the vitagene network and its possible biological relevance in metabolism homeostasis, the contribution of maternal resveratrol to redox status and vitagene systems need further to be explored.

Total plasma leptin/sOB- $\mathrm{R}$ ratio is considered a biological marker for leptin resistance [43-45]. BW decrease in obese adults is inclined to decrease the leptin/ sOB-R ratio, implying an improvement in leptin resistance [62]. Both maternal HF and postnatal HF diets led to increased leptin serum levels, but only postnatal HF decreased plasma sOB-R concentrations in the progeny. Prenatal resveratrol can attenuate plasma leptin but not change plasma sOB-R levels induced by prenatal and postnatal HF diet exposure. Apart from the central leptin resistance, which develops in the nervous system, peripheral leptin resistance has been observed in adipose tissue [63]. Obese individuals revealed a lower leptin receptor gene expression in adipose tissue than lean ones [64]. Although maternal resveratrol treatment did not enhance plasma sOB-R levels in this study, it was found that maternal resveratrol therapy augmented the gene expression of leptin receptors in the retroperitoneal fat depot. Thus, maternal resveratrol treatment appears to have a beneficial effect on the peripheral leptin resistance of progeny visceral fat tissue with prenatal and postnatal HFHS diet exposure.
The tendency to lower plasma triglycerides responses to post-weaning high-fat meals in $\mathrm{HH}$ and $\mathrm{HRH}$ groups, with respect to control meals in CC and $\mathrm{HC}$ groups, appears paradoxical in this study. This might be explained by diet components difference. In this study, the fat component of HFHS diet was provide by coconut oil. Coconut oil has been shown to decrease the triglyceride level for normal rats and hepatosteatosis condition attributed to its medium-chain saturated fatty acids [65-67].

\section{Study strengths and limitations}

The strength of this study is that it provide the potential and possible mechanism for maternal resveratrol in preventing the occurrence of metabolic syndrome related to prenatal or postnatal HFHS diet. This reprogramming effect for leptin resistance using prenatal resveratrol treatment is interesting, however, there are several limitations. First, to conclude metabolic regulation is difficult by solely measuring food intake and weight gain because food digestion/absorption can differ between groups, more data are needed to support it. Second, the effect of resveratrol on leptin and soluble leptin receptor may result from its beneficial effect on adiposity scores. Whether the obesity preventive effect of maternal resveratrol for progeny still exists with different diet components or different species also needs further testing. In this study, the plasma level of resveratrol and DNA methylation status of leptin receptors were not determined. The dose of resveratrol used in this study was about $10 \mathrm{mg} / \mathrm{kg} /$ day. In one report, plasma level of resveratrol was $96.5 \pm$ $12.3 \mathrm{nmol} / \mathrm{L}$ in rats with oral taking $20 \mathrm{mg} / \mathrm{kg} /$ day for $24 \mathrm{~h}$ [68]. In a recent report, Zou et al., have shown that 200 $\mathrm{mg} / \mathrm{kg} /$ day of resveratrol ameliorate the gestational weight gain in C57BL/6 J mice [56]. This protective effect for BW gain during pregnancy is not observed in this study (Supplementary Table 2). The dosage of resveratrol may account for this difference. The best therapeutic dosage and duration to re-program the prenatal/postnatal HF induced obesity for progeny also need to be identified.

\section{Conclusion}

In conclusion, maternal resveratrol treatment reprograms the adiposity programmed by maternal and postnatal HFHS diets through lipid metabolic modulation. It means maternal resveratrol supplementation can prevent obesity of progeny aggravated by prenatal and postnatal HF exposure. Maternal resveratrol can enhance SIRT1 abundance, decrease FAS gene expression, and promote $L P L$ gene expression in the retroperitoneal adipose depot programmed by combined maternal and postnatal HF diets. This study provides a new reprogramming role for the anti-obesity effect of maternal resveratrol supplements. 


\section{Supplementary information}

Supplementary information accompanies this paper at https://doi.org/10. 1186/s12944-020-01349-w.

Additional file 1: Supplementary Table 1. Primer sequences used for qRT-PCR. Supplementary Table 2. The body weight changes of dams in different groups. Supplementary Table 3. The birth body weight (BW) of offspring in different groups. Supplementary Table 4. The body weight of offspring in different groups.

\section{Abbreviations}

HF: High-fat; HFHS: High-fat/high-sucrose; SIRT1: Sirtuin 1; BW: Body weight; SD: Sprague-Dawley; FAS: Fatty acid synthase; LPL: Lipoprotein lipase; GAPD $\mathrm{H}$ : Glyceraldehyde 3-phosphate dehydrogenase; Ct: Threshold cycles; ANOVA: Analysis of variance; DOHaD: Developmental origins of health and disease; RT-qPCR: Quantitative reverse transcription-polymerase chain reaction; OB-R: Leptin receptor; CC: Soluble leptin receptor, maternal/postnatal control diet; HC: Maternal high-fat/postnatal control diet; $\mathrm{CH}$ : Maternal control/postnatal high-fat diet; HH: Maternal/postnatal high-fat diet; $\mathrm{HRH}$ : Maternal high-fat diet plus maternal resveratrol/postnatal high-fat diet

\section{Acknowledgements}

Not applicable.

\section{Authors' contributions}

Conceptualization, T-Y Liu, L-T Huang, C-C Tsai, and H-R Yu; Methodology, LT Huang, M-M Tiao, and J-M Sheen; Validation, Y-L Tain, I-C Lin, H-R Yu, and Y-J Lin.; Formal Analysis, T-Y Liu, I-C Lin, and Y-L Tain; Investigation, C-C Chen and C-C Tsai; Resources, M-M Tiao and H-R Yu; Data Curation, J-M Sheen and C-C Chen; Writing - Original Draft Preparation, T-Y Liu; Writing - Review \& Editing, T-Y Liu; Visualization, L-T Huang and Y-J Lin; Supervision, L-T Huang and $Y$-L Tain; Project Administration, Y-J Lin; Funding Acquisition, H-R Yu. The author (s) read and approved the final manuscript.

\section{Funding}

This research was funded in part by grants CMRPG8G0642 and 8 J0871 (H. R. Yu) from Chang Gung Memorial Hospital and MOST 107-2314-B-182 -044 -MY2 (H. R. Yu) from the Ministry of Science and Technology, Taiwan.

\section{Availability of data and materials}

The dataset supporting the conclusions of this article is available upon request for corresponding author after publication.

\section{Ethics approval and consent to participate}

The protocol was approved by the Institutional Animal Care and Use Committee of the Kaohsiung Chang Gung Memorial Hospital, Kaohsiung, Taiwan.

\section{Consent for publication}

Not applicable.

\section{Competing interests}

The authors declare that they have no competing interests.

Received: 6 May 2020 Accepted: 14 July 2020

Published online: 25 July 2020

\section{References}

1. Harris MI, Flegal KM, Cowie CC, Eberhardt MS, Goldstein DE, Little RR, Wiedmeyer HM, Byrd-Holt DD. Prevalence of diabetes, impaired fasting glucose, and impaired glucose tolerance in U.S. adults. The third National Health and nutrition examination survey, 1988-1994. Diabetes Care. 1998;21: 518-24.

2. Rose DP, Haffner SM, Baillargeon J. Adiposity, the metabolic syndrome, and breast cancer in African-American and white American women. Endocr Rev. 2007;28:763-77.

3. Harris MI. Diabetes in America: epidemiology and scope of the problem. Diabetes Care. 1998;21(Suppl 3):C11-4.
4. Olshansky SJ, Passaro DJ, Hershow RC, Layden J, Carnes BA, Brody J, Hayflick L, Butler RN, Allison DB, Ludwig DS. A potential decline in life expectancy in the United States in the 21st century. N Engl J Med. 2005;352:1138-45.

5. Felizardo RJ, da Silva MB, Aguiar CF, Camara NO. Obesity in kidney disease: a heavyweight opponent. World J Nephrol. 2014;3:50-63.

6. Chang Y, Ryu S, Choi Y, Zhang Y, Cho J, Kwon MJ, Hyun YY, Lee KB, Kim H, Jung HS, et al. Metabolically healthy obesity and development of chronic kidney disease: a cohort study. Ann Intern Med. 2016;164:305-12.

7. Messineo S, Laria AE, Arcidiacono B, Chiefari E, Luque Huertas RM, Foti DP, Brunetti A. Cooperation between HMGA1 and HIF-1 contributes to hypoxiainduced VEGF and Visfatin gene expression in 3T3-L1 adipocytes. Front Endocrinol (Lausanne). 2016;7:73.

8. Lepore SM, Maggisano V, Bulotta S, Mignogna C, Arcidiacono B, Procopio A, Brunetti A, Russo D, Celano M. Oleacein prevents high fat diet-induced adiposity and ameliorates some biochemical parameters of insulin sensitivity in mice. Nutrients. 2019;11:1829.

9. Ahima RS, Flier JS. Leptin. Annu Rev Physiol. 2000;62:413-37.

10. Loffreda S, Yang SQ, Lin HZ, Karp CL, Brengman ML, Wang DJ, Klein AS, Bulkley GB, Bao C, Noble PW, et al. Leptin regulates proinflammatory immune responses. FASEB J. 1998;12:57-65.

11. Thorburn AW, Ainslie DA, Fam B, Proietto J. Leptin in the pathophysiology of human obesity and the clinical potential of leptin-based therapy. BioDrugs. 2000;13:391-6.

12. Arcidiacono $B$, Chiefari $E$, Laria AE, Messineo $S$, Bilotta FL, Britti D, Foti DP, Foryst-Ludwig A, Kintscher U, Brunetti A. Expression of matrix metalloproteinase-11 is increased under conditions of insulin resistance. World J Diabetes. 2017;8:422-8.

13. Cohen SM, Werrmann JG, Tota MR. 13C NMR study of the effects of leptin treatment on kinetics of hepatic intermediary metabolism. Proc Natl Acad Sci U S A. 1998:95:7385-90.

14. Pelleymounter MA, Cullen MJ, Baker MB, Hecht R, Winters D, Boone T, Collins F. Effects of the obese gene product on body weight regulation in Ob/Ob mice. Science. 1995;269:540-3.

15. Guzik TJ, Korbut R, Adamek-Guzik T. Nitric oxide and superoxide in inflammation and immune regulation. J Physiol Pharmacol. 2003;54:469-87.

16. Mantzoros CS, Frederich RC, Qu D, Lowell BB, Maratos-Flier E, Flier JS. Severe leptin resistance in brown fat-deficient uncoupling protein promoter-driven diphtheria toxin a mice despite suppression of hypothalamic neuropeptide $Y$ and circulating corticosterone concentrations. Diabetes. 1998;47:230-8.

17. Hales CN, Barker DJ, Clark PM, Cox LJ, Fall C, Osmond C, Winter PD. Fetal and infant growth and impaired glucose tolerance at age 64. BMJ. 1991;303: 1019-22.

18. Haugen AC, Schug T, Collman G, Heindel JJ. Evolution of DOHaD: the impact of environmental health sciences. J Dev Orig Health Dis. 2015;6:55-64.

19. Wadhwa PD, Buss C, Entringer S, Swanson JM. Developmental origins of health and disease: brief history of the approach and current focus on epigenetic mechanisms. Semin Reprod Med. 2009;27:358-68.

20. Gillman MW. Developmental origins of health and disease. N Engl J Med. 2005;353:1848-50

21. Ganu RS, Harris RA, Collins K, Aagaard KM. Early origins of adult disease: approaches for investigating the programmable epigenome in humans, nonhuman primates, and rodents. ILAR J. 2012;53:306-21.

22. Flegal KM. Metabolically healthy overweight and obesity. Ann Intern Med. 2014;160:515-6.

23. Desai M, Jellyman JK, Han G, Beall M, Lane RH, Ross MG. Maternal obesity and high-fat diet program offspring metabolic syndrome. Am J Obstet Gynecol. 2014;211:237. e231-13.

24. Li S-W, Yu H-R, Sheen J-M, Tiao M-M, Tain Y-L, Lin I-C, Lin Y-J, Chang K-A, Tsai C-C, Huang L-T. A maternal high-fat diet during pregnancy and lactation, in addition to a postnatal high-fat diet, leads to metabolic syndrome with spatial learning and memory deficits: beneficial effects of resveratrol. Oncotarget. 2017;8:111998.

25. Chiefari E, Arcidiacono B, Foti D, Brunetti A. Gestational diabetes mellitus: an updated overview. J Endocrinol Investig. 2017:40:899-909.

26. Sanli E, Kabaran S. Maternal obesity, maternal Overnutrition and fetal programming: effects of epigenetic mechanisms on the development of metabolic disorders. Curr Genomics. 2019;20:419-27.

27. Samuelsson AM, Matthews PA, Jansen E, Taylor PD, Poston L. Sucrose feeding in mouse pregnancy leads to hypertension, and sex-linked obesity and insulin resistance in female offspring. Front Physiol. 2013:4:14. 
28. Oben JA, Patel T, Mouralidarane A, Samuelsson AM, Matthews P, Pombo J, Morgan M, McKee C, Soeda J, Novelli M, et al. Maternal obesity programmes offspring development of non-alcoholic fatty pancreas disease. Biochem Biophys Res Commun. 2010;394:24-8.

29. Fusco S, Spinelli M, Cocco S, Ripoli C, Mastrodonato A, Natale F, Rinaudo M, Livrizzi G, Grassi C. Maternal insulin resistance multigenerationally impairs synaptic plasticity and memory via gametic mechanisms. Nat Commun. 2019;10:1-17.

30. Tain Y-L, Hsu C-N. Developmental programming of the metabolic syndrome: can we reprogram with resveratrol? Int J Mol Sci. 2018;19:2584

31. Chou MY, Huang LT, Tain YL, Kuo HC, Tiao MM, Sheen JM, Chen CC, Hung PL, Hsieh KS, Yu HR. Age-dependent effects of prenatal dexamethasone exposure on immune responses in male rats. Tohoku J Exp Med. 2017;241: 225-37.

32. Procter SB, Campbell CG. Position of the academy of nutrition and dietetics: nutrition and lifestyle for a healthy pregnancy outcome. J Acad Nutr Diet. 2014;114:1099-103.

33. Yu J, Auwerx J. The role of sirtuins in the control of metabolic homeostasis. Ann N Y Acad Sci. 2009;1173(Suppl 1):E10-9.

34. Yu J, Auwerx J. Protein deacetylation by SIRT1: an emerging key posttranslational modification in metabolic regulation. Pharmacol Res. 2010;62: 35-41.

35. Diaz-Gerevini GT, Repossi G, Dain A, Tarres MC, Das UN, Eynard AR. Beneficial action of resveratrol: how and why? Nutrition. 2016;32:174-8.

36. Yu HR, Sheen JM, Tiao MM, Tain YL, Chen CC, Lin IC, Lai YJ, Tsai CC, Lin YJ, Tsai CC, et al. Resveratrol treatment ameliorates leptin resistance and adiposity programed by the combined effect of maternal and post-weaning high-fat diet. Mol Nutr Food Res. 2019;63:1801385.

37. Huang YC, Huang LT, Sheen JM, Hou CY, Yeh YT, Chiang CP, Lin IC, Tiao MM, Tsai CC, Lin YJ, et al. Resveratrol treatment improves the altered metabolism and related dysbiosis of gut programed by prenatal high-fat diet and postnatal high-fat diet exposure. J Nutr Biochem. 2020;75:108260.

38. Zheng S, Feng Q, Cheng J, Zheng J. Maternal resveratrol consumption and its programming effects on metabolic health in offspring mechanisms and potential implications. Biosci Rep. 2018;38.

39. Yu HR, Li SC, Tseng WN, Tain YL, Chen CC, Sheen JM, Tiao MM, Kuo HC, Huang CC, Hsieh KS, Huang LT. Early and late effects of prenatal corticosteroid treatment on the microRNA profiles of lung tissue in rats. Exp Ther Med. 2016;11:753-62.

40. Yu HR, Tain YL, Sheen JM, Tiao MM, Chen CC, Kuo HC, Hung PL, Hsieh KS, Huang LT. Prenatal dexamethasone and postnatal high-fat diet decrease interferon gamma production through an age-dependent histone modification in male Sprague-Dawley rats. Int J Mol Sci. 2016;17.

41. Yu HR, Tain YL, Tiao MM, Chen CC, Sheen JM, Lin IC, Li SW, Tsai CC, Lin YJ, Hsieh KS, Huang LT. Prenatal dexamethasone and postnatal high-fat diet have a synergistic effect of elevating blood pressure through a distinct programming mechanism of systemic and adipose renin-angiotensin systems. Lipids Health Dis. 2018;17:50

42. Hung CS, Lee JK, Yang CY, Hsieh HR, Ma WY, Lin MS, Liu PH, Shih SR, Liou JM, Chuang LM, et al. Measurement of visceral fat: should we include retroperitoneal fat? PLoS One. 2014;9:e112355.

43. Sandhofer A, Laimer M, Ebenbichler CF, Kaser S, Paulweber B, Patsch JR. Soluble leptin receptor and soluble receptor-bound fraction of leptin in the metabolic syndrome. Obes Res. 2003;11:760-8.

44. Owecki M, Nikisch E, Miczke A, Pupek-Musialik D, Sowinski J. Leptin, soluble leptin receptors, free leptin index, and their relationship with insulin resistance and BMI: high normal BMI is the threshold for serum leptin increase in humans. Horm Metab Res. 2010;42:585-9.

45. Herrick JE, Panza GS, Gollie JM. Leptin, Leptin soluble receptor, and the free Leptin index following a diet and physical activity lifestyle intervention in obese males and females. J Obes. 2016;2016:8375828.

46. Hsu MH, Sheen JM, Lin IC, Yu HR, Tiao MM, Tain YL, Huang LT. Effects of maternal resveratrol on maternal high-fat diet/obesity with or without postnatal high-fat diet. Int J Mol Sci. 2020;21.

47. Chang GQ, Gaysinskaya V, Karatayev O, Leibowitz SF. Maternal high-fat diet and fetal programming: increased proliferation of hypothalamic peptideproducing neurons that increase risk for overeating and obesity. J Neurosci. 2008;28:12107-19.

48. Mirabelli M, Chiefari E, Arcidiacono B, Corigliano DM, Brunetti FS, Maggisano $V$, Russo D, Foti DP, Brunetti A. Mediterranean diet nutrients to turn the tide against insulin resistance and related diseases. Nutrients. 2020;12:1066.
49. Baur JA, Pearson KJ, Price NL, Jamieson HA, Lerin C, Kalra A, Prabhu W, Allard JS, Lopez-Lluch G, Lewis K, et al. Resveratrol improves health and survival of mice on a high-calorie diet. Nature. 2006;444:337-42.

50. Baur JA, Sinclair DA. Therapeutic potential of resveratrol: the in vivo evidence. Nat Rev Drug Discov. 2006;5:493-506.

51. Beaudeux JL, Nivet-Antoine V, Giral P. Resveratrol: a relevant pharmacological approach for the treatment of metabolic syndrome? Curr Opin Clin Nutr Metab Care. 2010;13:729-36.

52. Izquierdo V, Palomera-Avalos V, Lopez-Ruiz S, Canudas AM, Pallas M, GrinanFerre C. Maternal resveratrol supplementation prevents cognitive decline in senescent mice offspring. Int J Mol Sci. 2019;20:1134.

53. Tanaka M, Kita T, Yamasaki S, Kawahara T, Ueno Y, Yamada M, Mukai Y, Sato S, Kurasaki M, Saito T. Maternal resveratrol intake during lactation attenuates hepatic triglyceride and fatty acid synthesis in adult male rat offspring. Biochem Biophys Rep. 2017;9:173-9.

54. Brawerman GM, Kereliuk SM, Brar N, Cole LK, Seshadri N, Pereira TJ, Xiang B, Hunt KL, Fonseca MA, Hatch GM, et al. Maternal resveratrol administration protects against gestational diabetes-induced glucose intolerance and islet dysfunction in the rat offspring. J Physiol. 2019;597:4175-92.

55. Menichini $D$, Longo M, Facchinetti F. Maternal interventions to improve offspring outcomes in rodent models of diet-induced obesity: a review. J Matern Fetal Neonatal Med. 2019;32:2943-9.

56. Zou T, Chen D, Yang Q, Wang B, Zhu MJ, Nathanielsz PW, Du M. Resveratrol supplementation of high-fat diet-fed pregnant mice promotes brown and beige adipocyte development and prevents obesity in male offspring. J Physiol. 2017;595:1547-62.

57. Repossi G, Das UN, Eynard AR. Molecular basis of the beneficial actions of resveratrol. Arch Med Res. 2020;51:105-14.

58. Calabrese V, Santoro A, Trovato Salinaro A, Modafferi S, Scuto M, Albouchi F, Monti D, Giordano J, Zappia M, Franceschi C, Calabrese EJ. Hormetic approaches to the treatment of Parkinson's disease: perspectives and possibilities. J Neurosci Res. 2018;96:1641-62.

59. Miquel S, Champ C, Day J, Aarts E, Bahr BA, Bakker M, Banati D, Calabrese V, Cederholm T, Cryan J, et al. Poor cognitive ageing: vulnerabilities, mechanisms and the impact of nutritional interventions. Ageing Res Rev. 2018;42:40-55.

60. Trovato Salinaro A, Pennisi M, Di Paola R, Scuto M, Crupi R, Cambria MT, Ontario ML, Tomasello M, Uva M, Maiolino L, et al. Neuroinflammation and neurohormesis in the pathogenesis of Alzheimer's disease and Alzheimer-linked pathologies: modulation by nutritional mushrooms. Immun Ageing. 2018;15:8.

61. Pilipenko V, Narbute K, Amara I, Trovato A, Scuto M, Pupure J, Jansone B, Poikans J, Bisenieks E, Klusa V, Calabrese V. GABA-containing compound gammapyrone protects against brain impairments in Alzheimer's disease model male rats and prevents mitochondrial dysfunction in cell culture. J Neurosci Res. 2019;97:708-26.

62. van Dielen FM, Van't Veer C, Buurman WA, Greve JW. Leptin and soluble leptin receptor levels in obese and weight-losing individuals. J Clin Endocrinol Metab. 2002;87:1708-16.

63. Carter S, Caron A, Richard D, Picard F. Role of leptin resistance in the development of obesity in older patients. Clin Interv Aging. 2013;8:829-44.

64. Seron K, Corset L, Vasseur F, Boutin P, Gomez-Ambrosi J, Salvador J, Fruhbeck G, Froguel P. Distinct impaired regulation of SOCS3 and long and short isoforms of the leptin receptor in visceral and subcutaneous fat of lean and obese women. Biochem Biophys Res Commun. 2006;348:1232-8.

65. Arunima S, Rajamohan T. Virgin coconut oil improves hepatic lipid metabolism in rats--compared with copra oil, olive oil and sunflower oil. Indian J Exp Biol. 2012;50:802-9.

66. Famurewa AC, Ekeleme-Egedigwe CA, Nwali SC, Agbo NN, Obi JN, Ezechukwu GC. Dietary supplementation with virgin coconut oil improves lipid profile and hepatic antioxidant status and has potential benefits on cardiovascular risk indices in Normal rats. J Diet Suppl. 2018;15:330-42.

67. Narayanankutty A, Palliyil DM, Kuruvilla K, Raghavamenon AC. Virgin coconut oil reverses hepatic steatosis by restoring redox homeostasis and lipid metabolism in male Wistar rats. J Sci Food Agric. 2018;98:1757-64.

68. Juan ME, Vinardell MP, Planas JM. The daily oral administration of high doses of trans-resveratrol to rats for 28 days is not harmful. J Nutr. 2002;132: 257-60.

\section{Publisher's Note}

Springer Nature remains neutral with regard to jurisdictional claims in published maps and institutional affiliations. 